\title{
Adsorbent for Di-n-butyl Phthalate using Chitosan Beads with Upper- or Lower-Rim Substituted Water-soluble Calixarenes
}

\author{
Akihiro YANAGI, ${ }^{1, \dagger}$ Hideyuki OTsuka, ${ }^{2}$ and Atsushi TAKAHARA ${ }^{2}$ \\ ${ }^{1}$ Oita Industrial Research Institute, 1-4361-10 Takae-nishi, Oita 870-1117, Japan \\ ${ }^{2}$ Institute for Materials Chemistry and Engineering, Kyushu University, \\ 6-10-1 Hakozaki, Higashi-ku, Fukuoka 812-8581, Japan
}

(Received May 10, 2005; Accepted August 19, 2005; Published December 15, 2005)

\begin{abstract}
The complexation of di- $n$-butyl phthalate (DBP) by two different series of water-soluble calixarenes $\{p$-sulfonatocalix $[n]$ arenes $[\mathbf{S C A} \boldsymbol{n}(n=4,6$, and 8$)]$ and calix $[n]$ arene- $O$-propane-3-sulfonate $[\mathbf{C A} \boldsymbol{n P S}(n=4,6$, and 8)] $\}$ and the DBP adsorption ability of chitosan beads modified with SCAn and CAnPS were investigated. The six- and eight-membered calixarenes (SCA6, SCA8, CA6PS, and CA8PS) could include DBP in their hydrophobic cavities in the homogeneous aqueous phase. The amount of DBP adsorbed by chitosan beads modified with SCA6 was approximately five times as large as that for unmodified chitosan beads. On the other hand, the chitosan beads modified with SCA8 show the nearly the same amount of adsorbed DBP as compared to unmodified chitosan beads. In the case of the chitosan beads modified with CAnPS, no correlation was observed with the DBP inclusion capability of CAnPS.

[DOI 10.1295/polymj.37.939]

KEY WORDS Calixarene / Chitosan / Di- $n$-butyl Phthalate / Inclusion / Adsorption / Polyion Complex /
\end{abstract}

Endocrine-disrupting chemicals (EDCs) and persistent organic pollutants have received considerable attention in recent years. Nonylphenol, 4-octylphenol, and bisphenol A have been reported to exhibit estrogenic activity, ${ }^{1-3}$ and various other chemicals are suspected to be EDCs. Alkyl phthalates are representative examples $^{4,5}$ and are still under investigation. These chemicals have been detected in rivers and sediments because of their widespread use as plasticizers. Activated carbon has generally been used as an adsorbent for organic pollutants in water. However, the breakthrough time of activated carbon is not long because the selectivity for adsorbates is insufficient, and thus, frequent reactivation of the used activated carbon becomes essential. In addition, a large amount of thermal energy is required for the reactivation process. These problems can be solved if an adsorbent with recognition ability is prepared. To this end, several studies have reported adsorbents with molecular recognition sites, e.g., the adsorbent with cyclodextrin that can adsorb bisphenol A and alkyl phthalates. ${ }^{6-8}$ If a receptor has a hydrophobic cavity formed by aromatic rings, strong interaction is expected between the receptor and the noxious hydrophobic chemicals. The authors proposed an adsorbent modified with calixarene, ${ }^{9}$ which is a cyclic oligomer that consists of aromatic rings crosslinked by methylene groups, as a binding site.

From a practical viewpoint, the convenient fabrica- tion of receptors and adsorbents is important. It is known that Calix $[n]$ arenes $(n=4,6$, and 8$)$ can be easily synthesized from $p$-alkylphenol and formaldehyde with good yields ${ }^{10-12}$ and can be easily modified by the introduction of functional groups into the $p$ position of the phenol (upper-rim) and phenolic hydroxyl group (lower-rim). ${ }^{13-15}$ Therefore, it is appropriate that these analogues are nominated as the basic skeleton of a alkyl phthalates receptor. As for the fabrication of the adsorbent, polyion complexation is one kind of convenient modification methods for polymers. Immobilization of anionic calixarenes can be achieved by a polyion complex formation with cationized polymers. In addition, the upper-rim and lowerrim of calixarenes can be easily substituted as previously described. Thus, we synthesized two series of anionic sulfonated calixarenes, i.e., $p$-sulfonatocalix$[n]$ arenes $[\mathbf{S C A} \boldsymbol{n}(n=4,6$, and 8$)]$ and calix $[n]$ arene$O$-propane-3-sulfonate [CAnPS $(n=4,6$, and 8)]. We also synthesized 2,6-dimethyl sulfonatophenol (DMSP) and 3-(2,6-dimethylphenoxy)propane-1-sulfonate (DMPPS) as references (Figure 1). With regard to the backbone of this adsorbent, hydrophilic polymers should be chosen so that the hydrophobic cavities of calixarenes can function effectively as molecular receptors driven by hydrophobic interaction with sizeselectivity. Therefore, an environmentally benign hydrophilic cationic polymer derived from the discarded shells of crabs and shrimp-chitosan was employed.

${ }^{\dagger}$ To whom correspondence should be addressed (Tel: +81-97-596-7100, Fax: +81-97-596-7005, E-mail: a-yanagi@oita-ri.go.jp). 


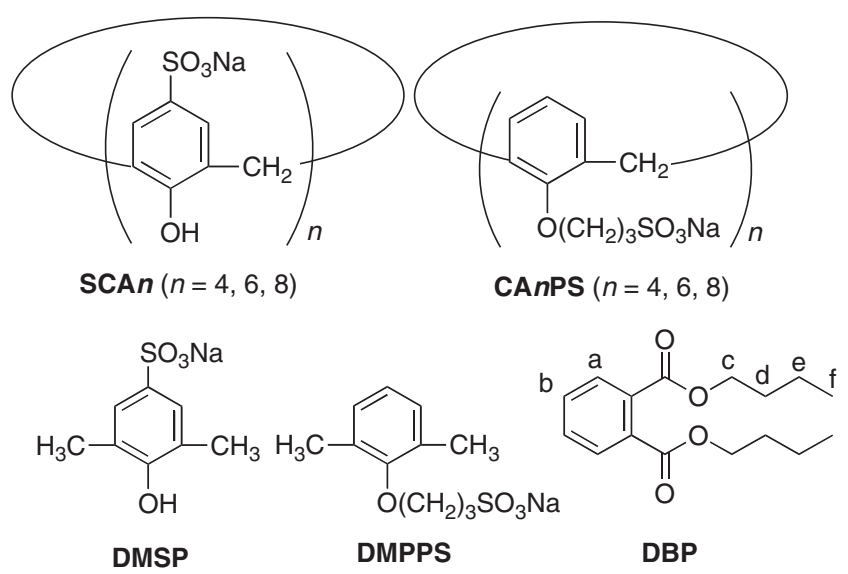

Figure 1. Chemical structures of sulfonated calixarenes, model acyclic compounds, and DBP.

In this paper, we chose di- $n$-butyl phthalate (DBP) as a target molecule because of the slightly higher water solubility of DBP among alkyl phthalates. We describe the DBP inclusion properties of the sulfonated calixarenes and the DBP adsorption ability of the chitosan beads modified with sulfonated calixarenes in an aqueous system. As for the fabrication of adsorbent with assembled receptors, it was supposed that the field with the assembled receptors on the adsorbent was different from the field formed by free receptors in the solution. Thus, we also describe the influence for the DBP adsorption from the field formed by the assembled receptors on the adsorbent.

\section{EXPERIMENTAL}

\section{General Procedures}

All chemicals were of commercial reagent quality and were used without further purification. SCA $\boldsymbol{n}^{16}$ and $\mathbf{C A n P S}{ }^{17}$ were synthesized by the reported method. DMSP and DMPPS were synthesized by the same methods as those for the corresponding compounds, as described later.

${ }^{1} \mathrm{H}$ NMR spectroscopic measurements were carried out at $298 \pm 2 \mathrm{~K}$ with a Bruker DPX-400 $(400 \mathrm{MHz})$, a JEOL JNM-EX400 (400 MHz), or a Bruker ARX$300(300 \mathrm{MHz})$. IR spectra were obtained with a JASCO FT/IR-700S infrared spectrometer using the $\mathrm{KBr}$ pellet method. X-Ray photoelectron spectroscopic (XPS) measurements were made with a Phi Quantum 2000 (Physical Electronics) using focused $(100 \mu \mathrm{m}$ spot) monochromatic $\mathrm{Al} K \alpha$ radiation at 15 $\mathrm{kV}$ and $1.3 \mathrm{~mA}$ with a pass energy of $29.35 \mathrm{eV}$. The UV spectra were measured on a Hitachi U-2000. Scanning electron microscopy (SEM) observations were made on a JEOL JSM-7400F operated at $5 \mathrm{kV}$ for the freeze-dried adsorbents with osmium coating.

\section{Syntheses of the Corresponding Monomeric Com- pounds}

DMSP. 2,6-Dimethylphenol $(7.1 \mathrm{~g}, 56.3 \mathrm{mmol})$ was mixed with $60 \mathrm{~cm}^{3}$ of concentrated $\mathrm{H}_{2} \mathrm{SO}_{4}$, and the solution was heated at $353 \mathrm{~K}$ for $2 \mathrm{~h}$. An aliquot was drawn from the solution and poured into water in order to monitor the progress of the reaction. The reaction was completed when no water-insoluble material was detected. After cooling, the reaction mixture was carefully poured into $150 \mathrm{~g}$ of ice water, and then the insoluble material was filtered off. The filtrate was washed with chloroform and treated with activated carbon. A white precipitate was then obtained from the filtrate by a salting-out method with $\mathrm{NaCl}$. The precipitate was dissolved in $60 \mathrm{~cm}^{3}$ of water and neutralized by $\mathrm{BaCO}_{3}$. Precipitated $\mathrm{BaSO}_{4}$ was removed by filtration and $\mathrm{Na}_{2} \mathrm{CO}_{3}$ was then added to the filtrate in order to exchange the counter cation. When the $\mathrm{pH}$ reached 8-9, the addition of $\mathrm{Na}_{2} \mathrm{CO}_{3}$ was stopped. The solution was filtrated and the obtained filtrate was concentrated to dryness. The residue was recrystallized from methanol and chloroform. Yield 64\%. Paper chromatography (PC) yielded a single spot on chromatography paper (water/2-propanol $=1 / 2 \mathrm{v} / \mathrm{v}$ ); m.p. > $573 \mathrm{~K}$; IR $\left(\mathrm{KBr}, \mathrm{cm}^{-1}\right) 3496(-\mathrm{OH}), 1182$, $1056\left(-\mathrm{SO}_{2}\right) ;{ }^{1} \mathrm{H}$ NMR $\left(\mathrm{D}_{2} \mathrm{O}, 300 \mathrm{MHz}, \mathrm{ppm}\right): \delta 7.22$ (s, $2 \mathrm{H}, \mathrm{ArH}), 2.04$ (s, 6H, $\mathrm{CH}_{3}$ ).

Anal. Calcd for $\mathrm{C}_{8} \mathrm{H}_{9} \mathrm{O}_{4} \mathrm{SNa} \cdot 0.2 \mathrm{CHCl}_{3}$ : C, 39.70\%; $\mathrm{H}, 3.74 \%$.

Found: C, $39.80 \%$; H, $3.85 \%$.

DMPPS. 2,6-Dimethylphenol $(2.5 \mathrm{~g}, 20 \mathrm{mmol})$ was mixed with $70 \mathrm{~cm}^{3}$ of THF, and the solution was refluxed for $1 \mathrm{~h}$ under a nitrogen atmosphere. After cooling, sodium hydride $(1.6 \mathrm{~g}, 40 \mathrm{mmol} ; 60 \%$ dispersion in oil) was added and the mixture was stirred for $1 \mathrm{~h}$. Propane-1,3-sultone $\left(3.6 \mathrm{~cm}^{3}, 40 \mathrm{mmol}\right)$ was then added dropwise and the mixture was stirred at room temperature for $22 \mathrm{~h}$. Excess $\mathrm{NaH}$ was decomposed with methanol, after which the mixture was diluted with water, and the insoluble material was filtered off. The filtrate was concentrated to approximately $50 \mathrm{~cm}^{3}$ and sodium acetate was added to salt out the sodium salt. The precipitate was washed with hot chloroform in order to remove residual propane-1,3sultone. Yield $81 \%$. PC yielded a single spot on chromatography paper (water/2-propanol $=1 / 2 \mathrm{v} / \mathrm{v}$ ); m.p. > $573 \mathrm{~K}$; IR $\left(\mathrm{KBr}, \mathrm{cm}^{-1}\right) 1192,1051\left(-\mathrm{SO}_{2}\right)$; ${ }^{1} \mathrm{H}$ NMR $\left(\mathrm{D}_{2} \mathrm{O}, 300 \mathrm{MHz}, \mathrm{ppm}\right): \delta 7.03(\mathrm{~d}, 2 \mathrm{H}, \mathrm{ArH})$, 6.94 (t, 1H, ArH), 3.87 (t, 2H, C-O- $\left.\mathrm{CH}_{2}\right), 3.05$ (t, 2H, $\left.\mathrm{S}-\mathrm{CH}_{2}\right), 2.15\left(\mathrm{~m}, 8 \mathrm{H}, \mathrm{OCH}_{2} \mathrm{CH}_{2}, \mathrm{CH}_{3}\right)$.

Anal. Calcd for $\mathrm{C}_{11} \mathrm{H}_{15} \mathrm{O}_{4} \mathrm{SNa} \cdot 0.2 \mathrm{CHCl}_{3}$ : C, $46.36 \%$; $\mathrm{H}, 5.28 \%$.

Found: C, 46.22\%; H, 5.32\%. 
Immobilization of the Molecular Receptors onto Chitosan Beads

In order to fabricate the adsorbent with the molecular receptors, the receptors bearing sulfonate groups were immobilized onto chitosan beads by polyion complexation. ${ }^{18}$ In the present study, we chose Chitopearl Basic AL-01 (AL-01), which is manufactured by Fuji Spinning Co., Ltd. (Tokyo, Japan). AL-01 comprises unsubstituted chitosan beads with a particle diameter of $74-210 \mu \mathrm{m}$.

The anionic molecular receptors were complexed onto the cationic AL-01 as follows: Four grams of AL-01 in $40 \mathrm{~cm}^{3}$ of water was added in $160 \mathrm{~cm}^{3}$ of $2.5 \mathrm{wt} \%$ acetic acid aqueous solution $(66.3 \mathrm{mmol})$. The aqueous solution of the molecular receptor was added dropwise in the AL-01 dispersion. The detailed conditions of the volume of water and the amount of the molecular receptors are shown in Table I. After stirring sufficiently, the precipitate was obtained by filtration and then washed with water until the $\mathrm{pH}$ of the filtrate reached approximately 7 . The obtained precipitate was used as adsorbent in further experiments. The ratios of the molecular receptor to the chitosan unit in the adsorbents were estimated from the ratios of sulfur in the molecular receptor to the nitrogen of chitosan in AL-01 by XPS.

\section{Inclusion of $\mathbf{D B P}$ in the Molecular Receptors}

The complexation behavior of SCAn, DMSP, CAnPS, or DMPPS as a molecular receptor with DBP was examined by a ${ }^{1} \mathrm{H}$ NMR measurement as follows $(400 \mathrm{MHz}, \mathrm{T}=298 \pm 2 \mathrm{~K}) .{ }^{19}$ A stock methanol- $d_{4}$ solution of DBP was added to $2.5-124 \mathrm{mM}$ of SCAn, DMSP, CAnPS, or DMPPS solution in $\mathrm{D}_{2} \mathrm{O}$. At this time, the concentration of DBP was maintained constant in the range $1.2-1.3 \mathrm{mM}$ and the host-guest solu-

Table I. The conditions of polyion complexation

\begin{tabular}{ccccc}
\hline Adsorbent & Receptor & $\begin{array}{c}\text { Mixed quantity } \\
\text { of receptor } \\
\left(\text { as }^{\text {phenol unit }}{ }^{\mathrm{a}}\right)\end{array}$ & $\begin{array}{c}\text { Water for } \\
\text { dissolving } \\
\text { receptor } \\
\left(\mathrm{cm}^{3}\right)\end{array}$ \\
\hline DMSP-C & DMSP & 12.4 & $(12.4)$ & 40 \\
SCA4-C & SCA4 & 3.10 & $(12.4)$ & 40 \\
SCA6-C & SCA6 & 2.07 & $(12.4)$ & 40 \\
SCA8-C & SCA8 & 1.55 & $(12.4)$ & 550 \\
DMPPS-C-H & DMPPS & 12.4 & $(12.4)$ & 40 \\
CA4PS-C-H & CA4PS & 3.10 & $(12.4)$ & 40 \\
CA6PS-C-H & CA6PS & 2.07 & $(12.4)$ & 200 \\
CA8PS-C-H & CA8PS & 1.55 & $(12.4)$ & 800 \\
DMPPS-C-L & DMPPS & 0.248 & $(0.248)$ & 40 \\
CA4PS-C-L & CA4PS & 0.062 & $(0.248)$ & 40 \\
CA6PS-C-L & CA6PS & 0.041 & $(0.248)$ & 40 \\
CA8PS-C-L & CA8PS & 0.031 & $(0.248)$ & 40 \\
\hline
\end{tabular}

${ }^{\mathrm{a} C a l c u l a t e d}$ from the number of phenol unit in receptor. tion contained $0.8 \%$ of methanol- $d_{4}$ from stock solutions. When SCA6 or SCA8 was used as a receptor, the association constants $\left(K_{\mathrm{a}}\right)$ were calculated using a nonlinear curve fitting of the aromatic signals of DBP. ${ }^{20}$

\section{DBP Adsorption Tests}

Adsorption tests for DBP on AL-01 modified with the molecular receptors were carried out in $300 \mathrm{~cm}^{3}$ Erlenmeyer flasks. One gram of the modified chitosan beads and $100 \mathrm{~cm}^{3}$ of $67 \mathrm{mM}$ phosphate buffer (pH 7.0) containing $10 \mathrm{mM}$ of DBP were placed in the flask and shaken for $24 \mathrm{~h}$ at $298 \mathrm{~K}$. The adsorbed DBP was extracted in $n$-hexane and detected by a UV spectrophotometer.

\section{RESULTS AND DISCUSSION}

DBP Inclusion Properties of the Sulfonated Calixarenes

Figure 2 shows the ${ }^{1} \mathrm{H}$ NMR spectra of DBP and DBP with SCA6 in $\mathrm{D}_{2} \mathrm{O}$. The signals attributed to
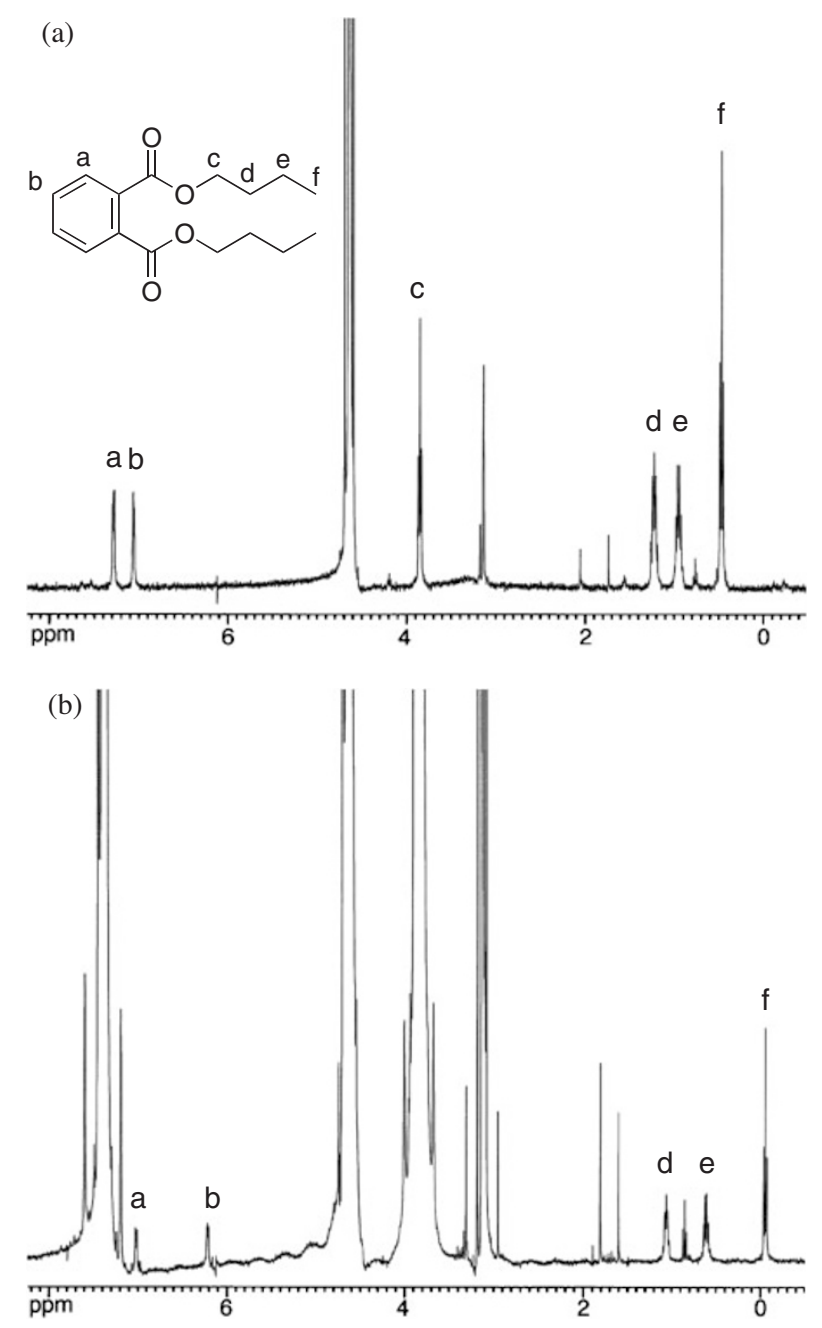

Figure 2. ${ }^{1} \mathrm{H}$ NMR spectra of (a) DBP and (b) DBP with SCA6 in $\mathrm{D}_{2} \mathrm{O}$ (with $0.8 \%$ of $\mathrm{CD}_{3} \mathrm{OD}$ ): [DBP], $1.24 \mathrm{mM}$; [SCA6], $61.5 \mathrm{mM}$. 

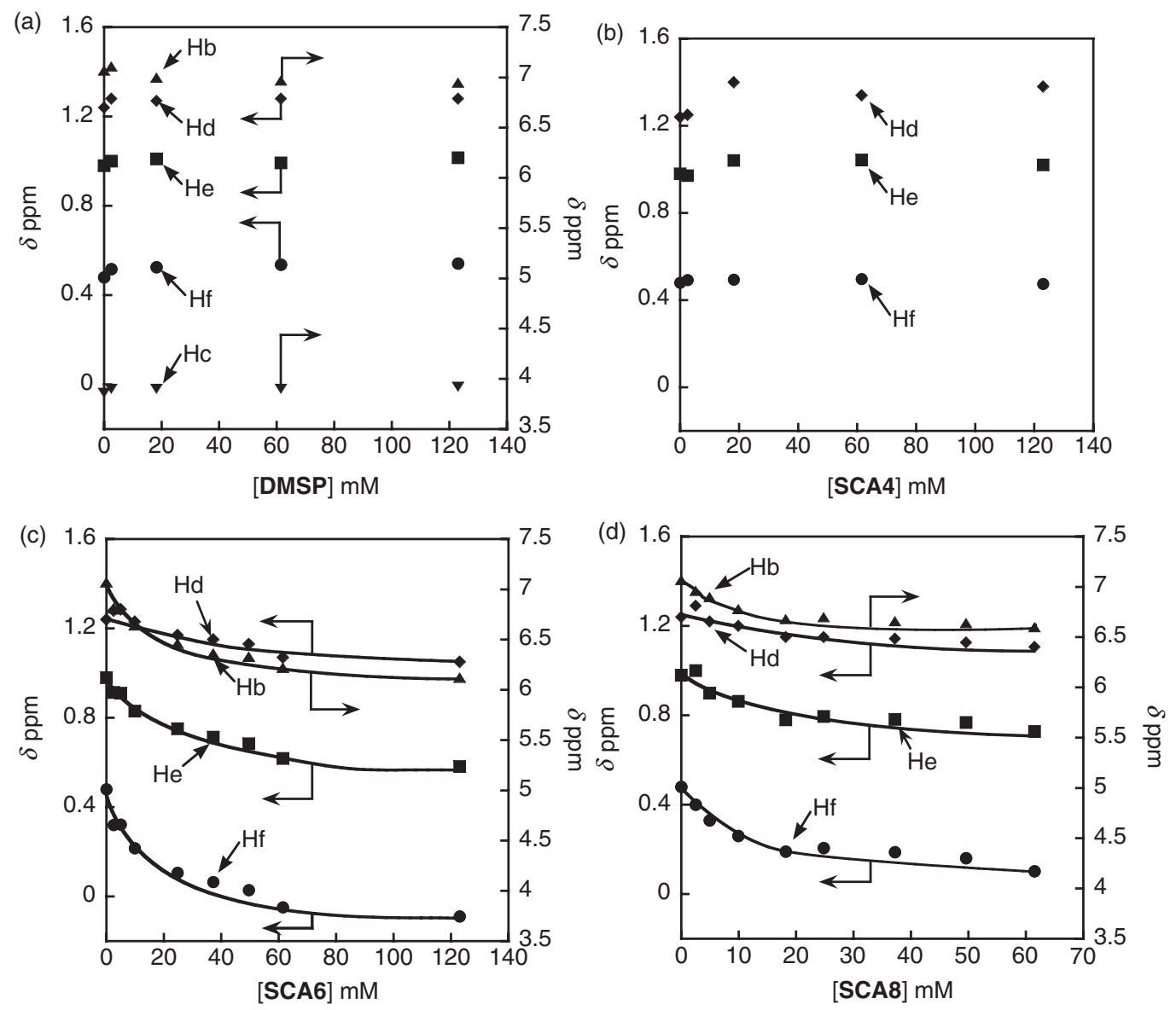

Figure 3. ${ }^{1} \mathrm{H}$ NMR chemical shift (in ppm) of DBP in $\mathrm{D}_{2} \mathrm{O}$ (with $0.8 \%$ of $\mathrm{CD}_{3} \mathrm{OD}$ ) in the presence of (a) DMSP; (b) SCA4; (c) SCA6; (d) SCA8.

the aromatic protons and the alkyl protons of DBP were shifted to a higher magnetic field in the presence of SCA6. These results were caused by the magnetic shielding effect of the aromatic rings of the host showing that SCA6 could include DBP in its cavity. The chemical shifts of the protons of DBP are plotted against several concentrations of SCA6 in Figure 3c. The signals due to DBP shifted to a higher magnetic field as the concentration of SCA6 was increased, and the plots of the signals were converged to each value. The $K_{\mathrm{a}}$ of SCA6 calculated from the Hb proton of DBP was $215 \mathrm{M}^{-1}$. The same tendency was observed in the case wherein SCA8 was used as a molecular receptor (Figure 3d). Therefore, SCA8 can bind DBP in the aqueous phase $\left(K_{\mathrm{a}}=372 \mathrm{M}^{-1}\right)$. The binding ability of SCA8 to DBP was stronger than that of SCA6 due to the flexible skeleton. In addition, when DMSP or SCA4 was used as a molecular receptor, the chemical shift of the protons of DBP did not shift to a higher magnetic field (Figures 3a and 3b). These results indicated that neither DMSP nor SCA4 included DBP.

Figure 4 shows the ${ }^{1} \mathrm{H}$ NMR chemical shifts of DBP when CAnPS or DMPPS was used as a molecular receptor in the same manner as SCAn or DMSP. This trend of the results was similar to that of the re- sults of SCAn and DMSP. CA6PS and CA8PS could include DBP in their cavities because the signals attributed to the alkyl protons of DBP were shifted to a higher magnetic field in the presence of CA6PS or CA8PS (Figures $4 \mathrm{c}$ and $4 d$ ). When CAnPS was used as a molecular receptor, the aromatic protons of DBP were not determined due to the overlap of the aromatic protons of CAnPS. Therefore, the $K_{\mathrm{a}}$ of CA6PS and CA8PS could not be estimated for comparison with SCA6 and SCA8. In the cases of CA4PS and DMPPS, there were no DBP inclusion phenomena similar to SCA4 and DMSP.

\section{Ratios of Molecular Receptors to Chitosan Unit in the Adsorbents}

Table II shows the ratios of the molecular receptors to the chitosan unit in adsorbents evaluated from XPS. The $S_{2 p} / N_{1 s}$ ratio had approximately the same value in each series, i.e., SCAn-C, CAnPS-C-H, and CAnPS-C-L $(n=4,6$, and 8). If the conformational structures and hole size of sulfonated calixarenes are not considered, then the hydrophobicities of the prepared chitosan beads were almost the same in the case of each corresponding compound, i.e., DMSP-C, DMPPS-C-H, or DMPPS-C-L. 

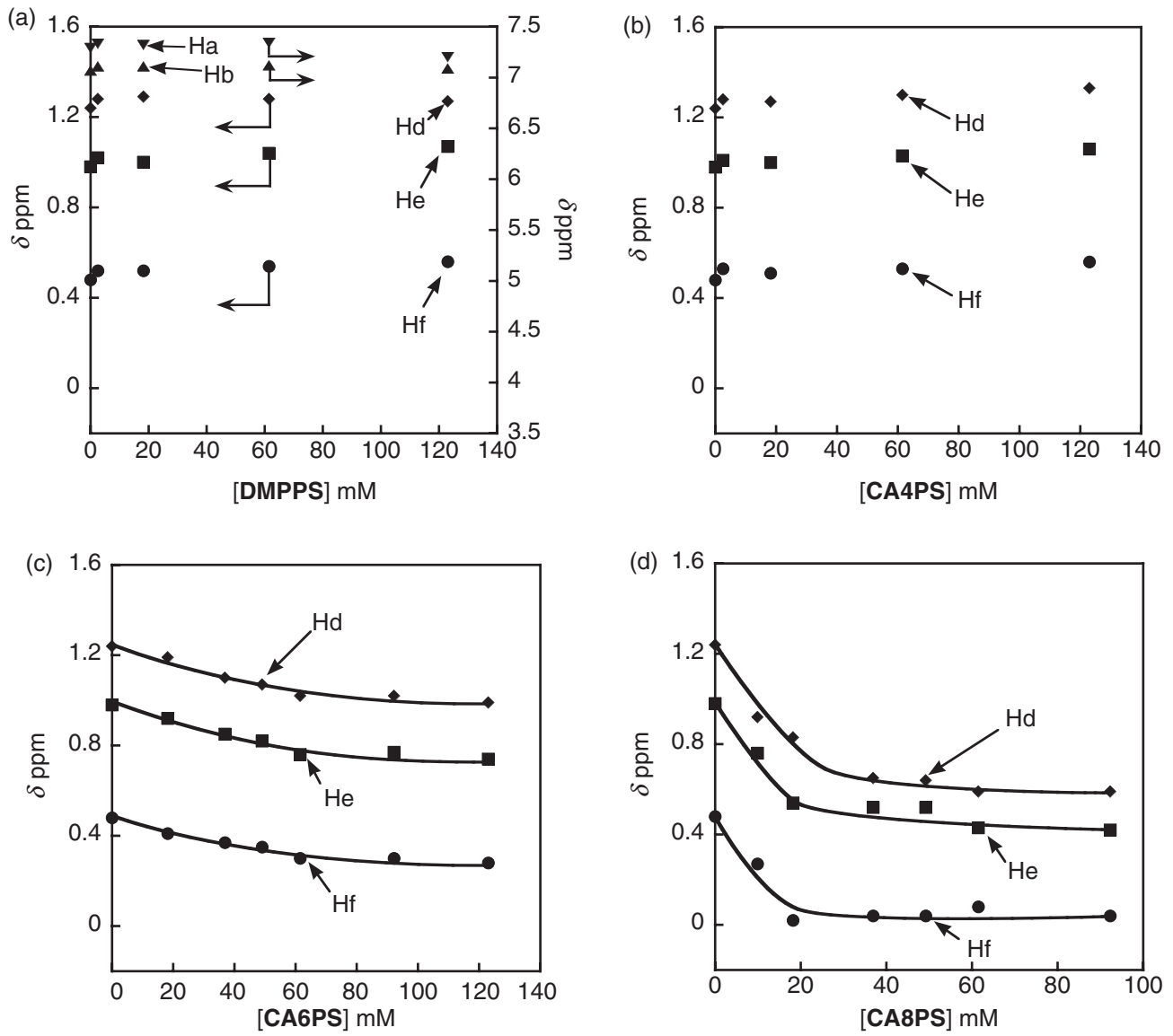

Figure 4. ${ }^{1} \mathrm{H}$ NMR chemical shift (in ppm) of DBP in $\mathrm{D}_{2} \mathrm{O}$ (with $0.8 \%$ of $\mathrm{CD}_{3} \mathrm{OD}$ ) in the presence of (a) DMPPS; (b) CA4PS; (c) CA6PS; (d) CA8PS.

Table II. Ratios of molecular receptors to chitosan in adsorbent determined by XPS

\begin{tabular}{ccccc}
\hline Adsorbent & Receptor & $\begin{array}{c}\text { Mixed quantity } \\
\text { of receptor a } \\
\text { phenol unit } \\
(\mathrm{mmol})\end{array}$ & $\begin{array}{c}\mathrm{S}_{2 \mathrm{p}} \text { (in receptor)/ } \\
\mathrm{N}_{1 \mathrm{~s}} \text { (in chitosan) }\end{array}$ & $\begin{array}{c}\text { Chitosan } \\
\text { unit:receptor }\end{array}$ \\
\hline DMSP-C & DMSP & 12.4 & $0.47\left(\sigma^{\mathrm{b}}=0.02\right)$ & $100: 47$ \\
SCA4-C & SCA4 & 12.4 & $0.65\left(\sigma^{\mathrm{b}}=0.03\right)$ & $100: 16.3$ \\
SCA6-C & SCA6 & 12.4 & $0.59\left(\sigma^{\mathrm{b}}=0.04\right)$ & $100: 9.8$ \\
SCA8-C & SCA8 & 12.4 & $0.63\left(\sigma^{\mathrm{b}}=0.04\right)$ & $100: 7.9$ \\
DMPPS-C-H & DMPPS & 12.4 & $0.55\left(\sigma^{\mathrm{b}}=0.05\right)$ & $100: 55$ \\
CA4PS-C-H & CA4PS & 12.4 & $0.79\left(\sigma^{\mathrm{b}}=0.04\right)$ & $100: 19.8$ \\
CA6PS-C-H & CA6PS & 12.4 & $0.77\left(\sigma^{\mathrm{b}}=0.05\right)$ & $100: 12.8$ \\
CA8PS-C-H & CA8PS & 12.4 & $0.86\left(\sigma^{\mathrm{b}}=0.05\right)$ & $100: 10.8$ \\
DMPPS-C-L & DMPPS & 0.248 & $0.18\left(\sigma^{\mathrm{b}}=0.02\right)$ & $100: 18$ \\
CA4PS-C-L & CA4PS & 0.248 & $0.23\left(\sigma^{\mathrm{b}}=0.03\right)$ & $100: 5.8$ \\
CA6PS-C-L & CA6PS & 0.248 & $0.26\left(\sigma^{\mathrm{b}}=0.07\right)$ & $100: 4.3$ \\
CA8PS-C-L & CA8PS & 0.248 & $0.31\left(\sigma^{\mathrm{b}}=0.07\right)$ & $100: 3.9$ \\
\hline
\end{tabular}

${ }^{\mathrm{a} C a l c u l a t e d ~ f r o m ~ t h e ~ n u m b e r ~ o f ~ p h e n o l ~ u n i t ~ i n ~ r e c e p t o r . ~}{ }^{\mathrm{b}} \sigma$ is a standard deviation calculated from 20 data.

Adsorption Properties of AL-01 Modified with the Molecular Receptors

Table III shows the DBP adsorption properties of the modified chitosan beads. SCA6-C had approximately five times the adsorption ability of unmodified chitosan beads. DMSP-C, SCA4-C, and SCA8-C did not show such a large improvement in adsorption. As described above, SCA8 showed a stronger binding ability to DBP than SCA6 in homogeneous aqueous solution, but SCA8-C showed poor adsorption ability. 
Table III. Adsorption of DBP by chitosan beads modified with molecular receptors

\begin{tabular}{cccc}
\hline Adsorbent & Receptor & $\begin{array}{c}\text { Chitosan unit: } \\
\text { immobilized } \\
\text { phenol unit }\end{array}$ & $\begin{array}{c}\text { Adsorbed } \\
\text { DBP } \\
\left(\mathrm{mg} \mathrm{g}^{-1}\right)\end{array}$ \\
\hline AL-01 & none & none & 11 \\
DMSP-C & DMSP & $100: 47$ & 26 \\
SCA4-C & SCA4 & $100: 65$ & 25 \\
SCA6-C & SCA6 & $100: 59$ & 57 \\
SCA8-C & SCA8 & $100: 63$ & 14 \\
DMPPS-C-H & DMPPS & $100: 55$ & $>80$ \\
CA4PS-C-H & CA4PS & $100: 79$ & $>80$ \\
CA6PS-C-H & CA6PS & $100: 77$ & $>80$ \\
CA8PS-C-H & CA8PS & $100: 86$ & $>80$ \\
DMPPS-C-L & DMPPS & $100: 18$ & $>80$ \\
CA4PS-C-L & CA4PS & $100: 23$ & $>80$ \\
CA6PS-C-L & CA6PS & $100: 26$ & 51 \\
CA8PS-C-L & CA8PS & $100: 31$ & 33 \\
\hline
\end{tabular}

This is probably due to the difference in the ring size and flexibility between SCA6 and SCA8. The ring size and flexibility of molecular receptors might play an important role in the complexation between DBP and a free molecular receptor. A large ring on the host would lead to an easy insertion of a guest and the flexible structure would change the conformation for suitable hydrophobic interaction between the host and guest. On the other hand, larger ring size and greater flexibility, which implies a large number of units, might cause the deformation (or loss) of the hydrophobic cavity by immobilization onto chitosan beads. Since SCA8 has eight sulfonate groups that can link to the amino groups in chitosan, anchoring by several methods as well as a large number of anchorings would limit the conformational changes of SCA8.

When CAnPS-C-H, DMPPS-C-H, CAnPS-C-L, and DMPPS-C-L were examined in adsorption test, the trend was entirely different from SCAn-C. The ratios of the immobilized phenol unit derived from molecular receptors to the chitosan unit in CAnPSC-H and DMPPS-C-H were approximately the same as the ratios in SCAn-C and DMSP-C, as shown in Table II. However, the amount of adsorbed DBP by CAnPS-C-H or DMPPS-C-H was significantly larger than that of SCAn-C or DMSP-C. For example, the DBP adsorption ability of DMPPS-C-H was three times as high as that of DMSP-C. The hydrophobicity of DMPPS is supposed to be high as compared to DMSP because DMPPS has an $O$-propane-1-sulfonate group instead of a phenolic hydroxyl group. Therefore, the adsorption of DBP by DMPPS-C-H would be caused by the hydrophobic domains formed by the homogeneously immobilized DMPPS. Corre-
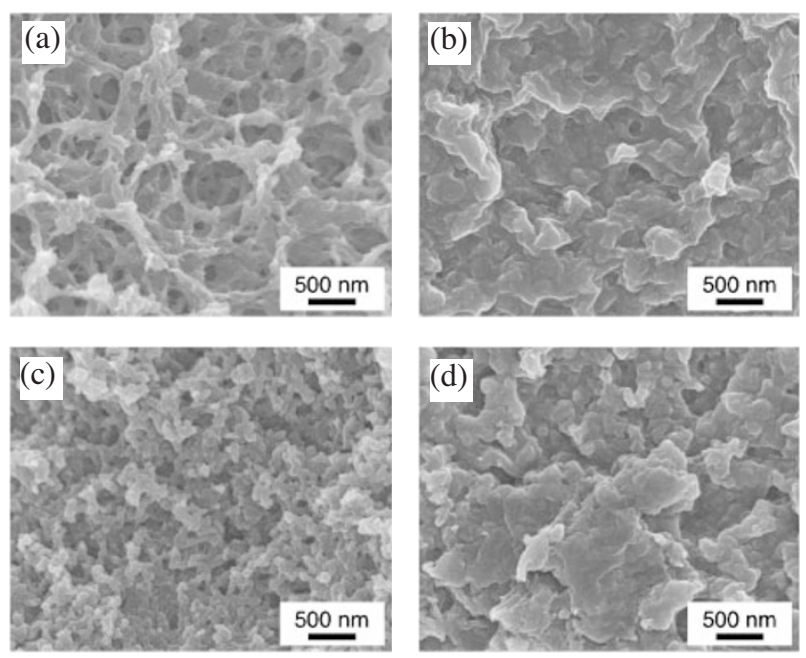

Figure 5. SEM images of (a) AL-01; (b) AL-01 treated with acetic acid (2.5 wt \%); (c) CA8PS-C-H; (d) CA8PS-C-L.

spondingly, the adsorption of DBP by CA6PS-C-H and CA8PS-C-H is considered to have occurred in the hydrophobic domains, which was formed by CA6PS and CA8PS, instead of the inclusion as previously described. This hypothesis was also supported by CA6PS-C-L and CA8PS-C-L, which decreased the ratios of the molecular receptor to the chitosan unit compared to CA6PS-C-H and CA8PS-C-H. The decrease in the immobilization ratio and the increase in the number of the ring member imply the sparse hydrophobic domains on the chitosan beads. Therefore, it appears that CA8PS-C-L showed poor adsorption ability as compared to CA4PS-C-L.

The Morphologies of AL-01 Modified with the Molecular Receptors

In order to evaluate the influence of the immobilization ratio of the calixarene derivatives to chitosan unit, SEM observation were carried out. Figure 5 shows the SEM images of (a) AL-01, (b) AL-01 treated with acetic acid (2.5 wt \%), (c) CA8PS-C-H, and (d) CA8PS-C-L coated by osmium after freeze-dried. CA8PS-C-H was observed as a porous body similar to AL-01. However, CA8PS-C-L was observed to dissolve the surface partially similar to AL-01 treated with acetic acid. CA8PS has eight sulfonate groups that can function as a crosslinker to amino groups in chitosan. The high immobilization ratio suggested the high crosslinking density. Therefore, the difference of the surface morphologies between CA8PSC-H and CA8PS-C-L was caused by the immobilization ratios of CA8PS. In other words, the morphology of CA8PS-C-L reflected the sparse immobilization of CA8PS (hydrophobic domains) compared with CA8PS-C-H. 


\section{CONCLUSIONS}

SCA6-C was shown to adsorb DBP in contrast to SCA8-C although SCA8 has a stronger binding ability to DBP than SCA6 has in the homogeneous aqueous solution. These results suggest that the conservation of the steric complementarity between a molecular receptor and a target molecule is of considerable importance to the fabrication of adsorbents with the immobilization of molecular receptors. In the case of AL-01 modified with CAnPS, no correlation was observed with the DBP inclusion abilities of CAnPS. It was probably caused by the hydrophobic domains, which is formed by CAnPS or DMPPS, instead of the inclusion. These results suggest the following: (1) the molecular receptor should be designed by considering the difference in the fields formed using a free receptor or assembled receptors and (2) the field should be fabricated such that the intermolecular interaction between molecular receptors and target molecules can perform effectively as molecular receptors.

Acknowledgment. This work was partially supported by "Nanotechnology Support Project" of the Ministry of Education, Culture, Sports, Science and Technology (MEXT), Japan.

\section{REFERENCES}

1. R. White, S. Jobling, S. A. Hoare, J. P. Sumpter, and M. G. Parker, Endocrinology, 135, 175 (1994).
2. K. W. Gaido, L. S. Leonard, S. Lovell, J. C. Gould, D. Babaï, C. J. Portier, and D. P. McDonnell, Toxicol. Appl. Pharmacol., 143, 205 (1997).

3. S. C. Laws, S. A. Carey, J. M. Ferrell, G. J. Bodman, and R. L. Cooper, Toxicol. Sci., 54, 154 (2000).

4. S. Jobling, T. Reynolds, R. White, M. G. Parker, and J. P. Sumpter, Environ. Health Perspect., 103, 582 (1995).

5. C. A. Harris, P. Henttu, M. G. Parker, and J. P. Sumpter, Environ. Health Perspect., 105, 802 (1997).

6. M. Nishiki, T. Tojima, N. Nishi, and N. Sakairi, Carbohydr. Lett., 4, 61 (2000).

7. S. Murai, S. Imajo, Y. Maki, K. Takahashi, and K. Hattori, J. Colloid Interface Sci., 183, 118 (1996).

8. S. Murai, S. Imajo, Y. Takasu, K. Takahashi, and K. Hattori, Environ. Sci. Technol., 32, 782 (1998).

9. A. Yanagi, H. Otsuka, and A. Takahara, Chem. Lett., 34, 218 (2005).

10. C. D. Gutsche and M. Iqbal, Org. Synth., 68, 234 (1990).

11. C. D. Gutsche, B. Dhawan, M. Leonis, and D. Steward, Org. Synth., 68, 238 (1990).

12. J. H. Munch and C. D. Gutsche, Org. Synth., 68, 243 (1990).

13. K. Araki, A. Yanagi, and S. Shinkai, Tetrahedron, 49, 6763 (1993).

14. V. Böhmer, Angew. Chem. Int. Ed., 34, 713 (1995).

15. A. Ikeda and S. Shinkai, Chem. Rev., 97, 1713 (1997).

16. S. Shinkai, H. Kawaguchi, and O. Manabe, J. Polym. Sci., Part C: Polym. Lett., 26, 391 (1988).

17. S. Shinkai, T. Arimura, K. Araki, H. Kawabata, H. Satoh, T. Tsubaki, O. Manabe, and J. Sunamoto, J. Chem. Soc., Perkin Trans. 1, 1989, 2039.

18. A. Tsuge, K. Masumi, T. Moriguchi, and K. Sakata, Aust. J. Chem., 51, 1175 (1998).

19. M. Baur, M. Frank, J. Schatz, and F. Schildbach, Tetrahedron, 57, 6985 (2001).

20. L. Fielding, Tetrahedron, 56, 6151 (2000). 